\title{
SOCIODEMOGRAPHIC FACTORS AFFECTING THE DISEASE ACCEPTANCE IN THE GROUP OF WOMEN WITH POSTMENOPAUSAL OSTEOPOROSIS
}

\section{BOGUMIŁA GÓRCZEWSKA and ELŻBIETA JAKUBOWSKA-PIETKIEWICZ}

\author{
Medical University of Lodz, Łódź, Poland \\ Department of Pediatrics, Neonatal Pathology and Bone Metabolism Diseases
}

\begin{abstract}
Objectives: Assessment of the disease acceptance level in women with osteoporosis depending on selected sociodemographic factors. Material and Methods: The study included a group of 198 women, aged $\mathrm{M} \pm \mathrm{SD} 72.3 \pm 8.59$ years, diagnosed with postmenopausal osteoporosis and treated in 2 Osteoporosis Treatment Centres in Łódź. A questionnaire survey and Acceptance of Illness Scale (AIS) were applied in the study. Based on the questionnaire, the authors collected sociodemographic data (including age, marital status, place of residence, financial status) which the authors subsequently analyzed using a statistical program. Results: The respondents living in the countryside, with primary education and a very difficult financial situation manifested a low disease acceptance level. The authors have shown that postmenopausal osteoporosis acceptance level significantly depends on the age $(p=0.0024)$, place of residence $(p=0.0044)$, education $(p<0.001)$ and affluence $(p=0.0049)$, however, it is not related to duration of the disease. Conclusions: Postmenopausal osteoporosis acceptance level depended on age, place of residence, education and affluence level, however, it was not related to the disease duration. Psychological aspects, including assessment according to the disease acceptance scale, constitute a factor influencing mental health, therefore they should be included in evaluation of therapy effectiveness in patients chronically treated for osteoporosis. Int J Occup Med Environ Health. 2022;35(3):273-83
\end{abstract}

Key words:

AIS, women, sociodemographic factors, osteoporosis, acceptance of disease, place of residence

\section{INTRODUCTION}

Osteoporosis is currently the most common chronic metabolic bone disease worldwide. It is estimated that it affects over 200 million people worldwide of which 75 million are citizens of Europe, USA and Japan [1,2]. The disease is more common in women than in men. The risk of osteoporosis increases more than sevenfold after the menopause [3]. Osteoporosis is a growing epidemiological problem in the rapidly ageing Polish society, and the complications associated with it, including bone fractures, are the reason for reduced quality of life, chronic disability and a significant increase in the risk of death [4]. The World Health Organization forecasts an increase in hip fractures from 1.7 million in 1990 to 6.3 million in $2050[5,6]$. Vertebral compression and bone fractures cause pain that may hinder activities of daily living, social activity and also lead to psychological consequences (among others, distress, anxiety, stress, depression) which are not assessed during medical appointments at outpatient osteoporosis treatment clinics.

Received: March 13, 2021. Accepted: September 29, 2021.

Corresponding author: Bogumiła Górczewska, Medical University of Lodz, Department of Pediatrics, Neonatal Pathology and Bone Metabolism Diseases, Sporna 36/50, 91-738 Łódź, Poland (e-mail: bogumila.gorczewska@umed.lodz.pl). 
Moreover, bone fractures result in long-term rehabilitation, hospitalization and expensive treatment, which affects the patient's mental state. Treatment should be aimed at minimizing the impact of the disease on the patient's life in a way that helps them to cope with negative emotions related to the diagnosed disease and applied therapy [7]. The patient's good mental state, i.e., acceptance of the situation, as well as the will to fight the disease, allows to achieve a better therapeutic outcome during treatment. For many patients, the acceptance of the disease is a problem they struggle with throughout its duration [8].

It is difficult for osteoporosis patients to accept, among others, a change in the body structure, limitations in physical activity, loss of a social role (withdrawal from professional and family life), chronic fear associated with the risk of bone fracture, anxiety related to chronic and expensive therapy. People's attitudes to a disease they suffer from, i.e., the meaning they assign to it and their beliefs about the impact it has (or does not have) on their somatic health, are related to the level of acceptance of limitations resulting from the disease. Hence, the way patients perceive their condition determines whether they adjust to it in an adaptive manner [9]. The problem is often not the disease itself but the lack of its acceptance by the patient. Improper, negative perception of one's own illness and regarding it as a threat, punishment or obstacle, negatively correlates with its acceptance. On the other hand, a belief in internal health control is positively associated with that acceptance [9]. Chronic disease imposes changes in life. Therefore people who accept certain limitations have a sense of control over their own lives. According to Gościcka [10], in order to achieve a high level of disease acceptance, collaborative efforts and activities should be taken and coordinated by a therapeutic team, family environment and the patient's professional group acquired. The disease acceptance level is a very impor- tant parameter influencing the mental state of a person. It also provides information on the patient's adaptation to the disease. The aim of the study was to evaluate the correlation between sociodemographic factors of women with postmenopausal osteoporosis and their acceptance of the disease.

\section{MATERIAL AND METHODS \\ Study design and population}

The study enrolled 198 postmenopausal women aged $72.3 \pm 8.59$ years (age range $51-90$ years) and was conducted in June 2018-May 2019. The patients were examined in 2 Osteoporosis Treatment Outpatient Clinics in Łódź, Poland.

The following exclusion criteria were applied:

- active cancer,

- malignant bone metastases,

- failure to complete the Acceptance of Illness Scale (AIS) questionnaire in full,

- secondary osteoporosis,

- glucocorticoids therapy,

- currently broken bones,

- hospitalization within the last 6 months.

The researcher presented information brochures about the purposefulness and course of the survey to all women who waited for an appointment in the clinic waiting room. Women who agreed to take part in the study were individually invited to a separate office at the clinic where they gave their informed consent to participate in the study and filled out questionnaires (at the same time they had an opportunity to ask questions to the researcher).

Out of 221 women who agreed to participate in the study, 198 correctly filled in the questionnaires. Only about $20 \%$ of women did not give their consent to take part in the study.

The survey was voluntary and conducted in accordance with the principles of human research specified 
in the Helsinki Declaration. The respondents signed an informed consent form and were advised that the study was to be conducted in compliance the currently applicable regulations and the provisions of the General Data Protection Regulation (GDPR). The study was approved by the Bioethics Committee of the Medical University of Lodz (Resolution No. RNN/215/18KE of 12th June 2018).

\section{Questionnaires}

The research method involved a diagnostic survey applying the following tools:

- the author's survey questionnaire, consisting of questions about sociodemographic data (including age, marital status, place of residence, financial status);

- the AIS - originally developed by Felton and Revenson [11]. In this study, the Polish version of the AIS, which was adapted by Juczyński [12], was used.

The Acceptance of Illness Scale consists of 8 statements assessed on a 5-point scale and it provides information on the patient's acceptance of the disease. To each statement, the respondent assigns one number from 1 ("I strongly agree") to 5 ("I strongly disagree") which describes his or her current state of health best. The sum of all points obtained is a measure of the disease acceptance degree. The possible score ranges 8-40 pts. After adding up all obtained points, interpretations are made according to 3 baseline scores. A score $<18$ pts means poor acceptance of the disease, a result ranging 19-29 pts means moderate acceptance of the illness, and obtaining $>29$ pts is a determinant of full acceptance and adaptation to the disease $[13,14]$. To sum up, the more points the patient obtains, the higher acceptance of his or her own condition.

Body mass index (BMI) was calculated in the surveyed women. The obtained result should be interpreted according to the BMI for the following persons: underweight (BMI $<18.0 \mathrm{~kg} / \mathrm{m}^{2}$ ), normal weight
(BMI 18.0-24 $\mathrm{kg} / \mathrm{m}^{2}$ ), overweight (BMI 25.00$29.9 \mathrm{~kg} / \mathrm{m}^{2}$ ), obesity (BMI $30-34.9 \mathrm{~kg} / \mathrm{m}^{2}$ ).

For the purpose of socio-demographic factors evaluation, the respondents were classified into groups. The authors made this division based on an earlier analysis of publications in such databases as PubMed, Scopus. When completing the questionnaire, the women provided information on, among others, education, place of residence and marital status. For the analysis of living conditions, a division according to the data of the Central Statistical Office was used - the report of the European Survey of Income and Living Conditions of the Polish Population (EU-SILC 2019 survey). The participants were divided into 4 groups according to the average (gross) annual income/ adult:

- very poor - income <PLN 21805 ,

- poor/bad - PLN 21 805-28 004,

- good - PLN 28 005-35 633,

- very good - > PLN 35633.

The authors used a measure to categorize the time since the osteoporosis diagnosis and the age of women, which allowed us to obtain a more or less uniform research group.

\section{Statistical analysis}

The results obtained from the questionnaires were statistically analyzed. The descriptive values of the analyzed variables were presented using the mean, median, standard deviation, minimum and maximum values. The Shapiro-Wilk test was used to test the normality of the distribution of quantitative variables. Between group comparisons for quantitative variables were fitted using the Kruskal-Wallis test, and for post-hoc pair-wise comparisons, Dunn's test was performed.

The relationships between numerical variables were assessed using the Pearson correlation ( $r$ ) coefficient. The adopted level of statistical significance was $\mathrm{p}<0.05$. The statistical analysis was made using the Statistica v. 13 Dell Inc. program (StatSoft, Poland). 


\section{RESULTS}

\section{Characteristics of the study population}

Characteristics of the study group: 198 women with postmenopausal osteoporosis were included in the survey. The average age was 72.3 years $(S D=8.59)$ (age range: 51-90 years). A vast majority of the subjects had abnormal body weight: BMI M \pm SD $25.71 \pm 4.73 \mathrm{~kg} / \mathrm{m}^{2}$.

Nearly half of the respondents were married. Most of them had secondary and higher education. A vast majority of the subjects $(\mathrm{N}=112)$ lived in a city of $>100000$ inhabitants. General information is presented in Table 1.

In the study group, osteoporosis was diagnosed at the age of $\mathrm{M} \pm \mathrm{SD} 61.82 \pm 9.74$. In turn, the duration of osteoporosis among the respondents was $\mathrm{M} \pm \mathrm{SD} 10.7 \pm 8.53$ years. In addition, $29 \%$ of the respondents $(\mathrm{N}=57)$ stated that the disease occurred in their immediate family, in 56\% $(\mathrm{N}=32)$ in mothers and in $31 \%(\mathrm{~N}=18)$ in sisters of the surveyed women.

\section{Acceptance of Illness Scale analysis}

The women with postmenopausal osteoporosis accepted their disease at a moderate level. The average AIS score for the whole group amounted to $25.95 \mathrm{pts}$ ( $\mathrm{SD}=10.2 \mathrm{pts}$, Me 26 pts, min.-max 8-40 pts indicating that the respondents did not feel the negative impact of OP significantly and accepted their health condition.

Then, the analysis of the disease acceptance level according to the general classification of the AIS (Table 2) showed that the predominant group, i.e., $41 \%$, were women with a high level of disease acceptance. A low level of disease acceptance was found in $30 \%$ of the respondents.

At the next stage, the authors analyzed individual elements of the AIS (Table 3). The interpretation of the results was based on the following relationship: the fewer the points, the greater the degree of agreement with a specific statement. The respondents agreed most with the statement "I will never be self-sufficient to the extent I would like to be" (M \pm SD 2.85 \pm 1.62 pts). Furthermore, due to the stage of the disease, they indicated the statement "I cannot do what I like because of my health condition" ( $\mathrm{M} \pm \mathrm{SD} 2.92 \pm 1.6 \mathrm{pts})$. Moreover, the women admitted that owing to the illness "My health condition makes me feel not a person of good value" $(\mathrm{M} \pm \mathrm{SD} 2.96 \pm 1.57 \mathrm{pts})$. The respondents agreed least with the following statements: "I think people around me often feel embarrassed because of my illness" ( $\mathrm{M} \pm \mathrm{SD} 3.67 \pm 1.51 \mathrm{pts})$ and "My illness makes me a burden for my family and friends" ( $\mathrm{M} \pm \mathrm{SD} 3.58 \pm 1.47 \mathrm{pts})$.

Then, selected factors influencing the level of disease acceptance were analyzed. The statistical analysis showed a significant relationship between the age of the respondents and their level of disease acceptance $(\mathrm{p}=0.0024)$ (Table 4 ). Over $8 \%$ of the women aged $50-60$ years showed a high level of disease acceptance. A low level of disease acceptance was found among those aged 81 years, which means that the disease acceptance decreased with age. Table 4 presents the influence of selected sociodemographic factors on the level of disease acceptance. When analyzing the study results, a statistically significant correlation was found between the respondents' education and their level of disease acceptance $(\mathrm{p}<0.001)$. Interpretation of the AIS average scores showed that the participants with primary education had a low level of disease acceptance. A statistically significant relationship was also observed between the women's place of residence and their disease acceptance level ( $\mathrm{p}=0.0044)$. There was a low level of disease acceptance among subjects living in the countryside, whereas it was at a moderate level among the city-dwellers. It was also shown that marital status affected the acceptance of the disease $(\mathrm{p}=0.0049)$. On the other hand, poor financial situation of the respondents was related to the low level of disease acceptance $(\mathrm{p}<0.001)$.

Based on the analysis of the patients' medical records it was possible to estimate osteoporosis duration (from the moment of the diagnosis to the examination). 
Table 1. Characteristics of postmenopausal women diagnosed with postmenopausal osteoporosis and treated in 20 steoporosis Treatment Centres in Łódź, Poland, June 2018-May 2019

\begin{tabular}{|c|c|c|}
\hline \multirow[t]{2}{*}{ Variable } & \multicolumn{2}{|c|}{$\begin{array}{c}\text { Participants } \\
(\mathrm{N}=198)\end{array}$} \\
\hline & $n$ & $\%$ \\
\hline \multicolumn{3}{|l|}{ Age } \\
\hline $50-60$ years & 17 & 9 \\
\hline $61-70$ years & 71 & 36 \\
\hline $71-80$ years & 74 & 37 \\
\hline $81-95$ years & 36 & 18 \\
\hline \multicolumn{3}{|l|}{ Education } \\
\hline primary & 41 & 21 \\
\hline vocational & 37 & 19 \\
\hline secondary & 70 & 35 \\
\hline higher & 50 & 25 \\
\hline \multicolumn{3}{|l|}{ Marital status } \\
\hline never married & 14 & 7 \\
\hline married or in a civil partnership & 93 & 47 \\
\hline widowed & 72 & 36 \\
\hline divorced & 19 & 10 \\
\hline \multicolumn{3}{|l|}{ Place of residence } \\
\hline village & 17 & 9 \\
\hline \multicolumn{3}{|l|}{ town } \\
\hline$<50000$ residents & 26 & 13 \\
\hline $50000-100000$ residents & 112 & 56 \\
\hline$>100000$ residents & 43 & 22 \\
\hline \multicolumn{3}{|l|}{ BMI } \\
\hline underweight $\left(\mathrm{BMI}<18.0 \mathrm{~kg} / \mathrm{m}^{2}\right)$ & 13 & 6.5 \\
\hline normal weight (BMI 18.0-24.9 kg/m²) & 78 & 39.5 \\
\hline overweight (BMI $25.00-29.9 \mathrm{~kg} / \mathrm{m}^{2}$ ) & 75 & 38 \\
\hline obesity (BMI 30-34.9 kg/m²) & 32 & 16 \\
\hline \multicolumn{3}{|l|}{ Osteoporosis duration } \\
\hline $1-5$ years & 62 & 31 \\
\hline $6-10$ years & 60 & 30 \\
\hline $11-15$ years & 29 & 14.5 \\
\hline $16-20$ years & 34 & 18 \\
\hline$>20$ years & 13 & 6.5 \\
\hline
\end{tabular}

\begin{tabular}{lcc}
\hline & Variable & \multicolumn{2}{c}{$\begin{array}{c}\text { Participants } \\
(\mathrm{N}=198)\end{array}$} \\
\cline { 2 - 3 } & $\mathrm{n}$ & $\%$ \\
\hline Living conditions & 17 & 8.5 \\
very good & 105 & 53 \\
good & 51 & 26 \\
poor/bad & 25 & 12.5 \\
very poor & & \\
\hline
\end{tabular}

Table 2. The disease acceptance level according to the general Acceptance of IIIness Scale (AIS) classification [13,14]

\begin{tabular}{lcc}
\hline \multirow{2}{*}{ Acceptance of IIIness Scale } & \multicolumn{2}{c}{$\begin{array}{c}\text { Participants } \\
\text { (N=198) }\end{array}$} \\
\cline { 2 - 3 } & $\mathrm{n}$ & $\%$ \\
\hline Low level (8-18 pts) & 59 & 30 \\
Moderate level (19-29 pts) & 57 & 29 \\
High level (30-40 pts) & 82 & 41 \\
\hline
\end{tabular}

It ranged from 1 to $>20$ years. There was no significant correlation between osteoporosis duration in the respondents and their disease acceptance level (Table 4).

The measured acceptance of illness (with AIS) among the study participants statistically significantly differed (analyzed post-hoc) by their level of education $(\mathrm{p}<0.001)$, place of residence $(\mathrm{p}=0.0044)$, material status $(\mathrm{p}=0.0049)$, living conditions $(\mathrm{p}<0.0001)$ and age $(\mathrm{p}<0.001)$.

\section{DISCUSSION}

The conducted study and the statistical analysis of the results provided data to assess the disease acceptance level in women with postmenopausal osteoporosis and to examine the impact of factors influencing the disease acceptance level. The overall score obtained ( $\mathrm{M} \pm \mathrm{SD} 25.95 \pm 10.2 \mathrm{pts})$, according to the AIS interpretation, showed that patients with postmenopausal osteoporosis accepted their health status at a moderate level. The disease acceptancelevel comparable to those results and assessed on the AIS (27.3 pts), 
Table 3. Descriptive statistics of statements given by the respondents on the Acceptance of IIIness Scale (AIS) in 2 Osteoporosis Treatment Centres in Łódź, Poland, June 2018-May 2019

Acceptance of IIIness Scale score

\begin{tabular}{lcc}
\hline \multicolumn{1}{c}{ Statement } & \multicolumn{2}{c}{ Acceptance of Illness Scale score } \\
& [pts] \\
\cline { 2 - 3 } & M & SD \\
\hline 1."I have problems with adapting to limitations imposed by my illness" & 3.11 & 1.67 \\
2."I cannot do what I like because of my health condition" & 2.92 & 1.60 \\
3. "My illness sometimes makes me feel unwanted" & 3.52 & 1.55 \\
4. "My health problems make me rely on others more than I want to" & 3.30 & 1.56 \\
5. "My illness makes me a burden for my family and friends" & 3.58 & 1.47 \\
6. "My health condition makes me feel not a person of good value" & 2.96 & 1.57 \\
7."I will never be self-sufficient to the extent I would like to be" & 2.85 & 1.62 \\
8."Ithink people around me often feel embarrassed because of my illness" & 3.67 & 1.51 \\
\hline
\end{tabular}

Scale interpretation: the fewer the points, the greater the agreement with the statement. Score: $1-5$ pts.

was obtained in the study by Pawlikowska-Łagód et al. [8], in which 137 women with osteoporosis were examined. Also in another study assessing disease acceptance, 207 patients treated for osteoporosis showed a moderate level of disease acceptance ( \pm SD 22.2 $\pm 6.9 \mathrm{pts})$ [14]. In the above-mentioned studies, as in the group of respondents in this study, after a detailed analysis of the AIS statements, it was shown that the subjects were aware of limitations associated with osteoporosis, which means that they will never be self-sufficient to the extent that they would like to be $[8,14]$.

The obtained results are comparable with those referring to disease acceptance levels in other chronic diseases. A moderate level of disease acceptance was demonstrated in patients with chronic obstructive pulmonary disease, multiple sclerosis (24.59 pts), psoriasis (24 pts), unstable angina ( $\mathrm{M} \pm \mathrm{SD} 21.52 \pm 6.89 \mathrm{pts})$, in hemodialysed patients with chronic renal failure (24.82 pts), in patients with epilepsy (M $\pm S D 25.05 \pm 5.23 \mathrm{pts})$,in patients treated for mental disorders: anxiety disorders ( $\mathrm{M} \pm \mathrm{SD} 24.41 \pm 8.52 \mathrm{pts})$, depression $(\mathrm{M} \pm \mathrm{SD} 22.80 \pm 7.51 \mathrm{pts})$ and personality disorders $(\mathrm{M} \pm \mathrm{SD} 23.89 \pm 7.89$ pts) [10,12,15-19]. Although the point values differ from each other, they are within the range that indicates a moderate level of disease acceptance among the respondents (19-29 pts). It should be kept in mind that adapting to the diagnosis and acceptance of the disease is a very important parameter influencing the mental state of a person and may be crucial in chronic patient treatment.

In the available literature, many authors obtained a moderate level of disease acceptance in patients with an oncological disease, such as breast cancer (AIS $\mathrm{M} \pm \mathrm{SD}$ $26.53 \pm 7.71 \mathrm{pts}$ ), colorectal cancer AIS = $27.74 \mathrm{pts}$, lung cancer AIS $=27.1$ pts, bladder cancer AIS $=28.8$ pts [20-24]. Therefore, it may be concluded that the level of disease acceptance in the study group was comparable to that observed in the case of neoplastic diseases, which means that patients with osteoporosis had little knowledge of the aetiology, course and complications of the disease. Thus, it is so important to spread information on osteoporosis in the population and to promote a healthy and active lifestyle. According to the authors, knowledge of the disease in Poland and in populations of other countries is insufficient in terms of its prophylaxis and prevention $[4,25]$. That is confirmed by the results of the study conducted in the Polish population by Janisze- 
Table 4. Characteristics of the study group of postmenopausal women diagnosed with postmenopausal osteoporosis and treated in 2 Osteoporosis Treatment Centres in Łódź, Poland, June 2018-May 2019, according to selected sociodemographic data

\begin{tabular}{|c|c|c|c|}
\hline Variable & $\begin{array}{c}\text { Participants } \\
(\mathrm{N}=198) \\
{[\mathrm{n}]}\end{array}$ & $\begin{array}{c}\text { Acceptance of Illness Scale } \\
{[\mathrm{pts}]} \\
(\mathrm{M} \pm \mathrm{SD})\end{array}$ & $p^{*}$ \\
\hline Age & & & 0.0024 \\
\hline $50-60$ years & 17 & $34.64 \pm 1.47$ & \\
\hline $61-70$ years & 71 & $26.72 \pm 6.34$ & \\
\hline $71-80$ years & 74 & $25.63 \pm 8.71$ & \\
\hline $81-95$ years & 36 & $18.43 \pm 7.46$ & \\
\hline Education & & & 0.0000 \\
\hline primary & 41 & $17.60 \pm 7.91$ & \\
\hline vocational & 37 & $27.35 \pm 9.80$ & \\
\hline secondary & 70 & $28.84 \pm 9.97$ & \\
\hline higher & 50 & $27.70 \pm 9.04$ & \\
\hline Marital status & & & 0.0049 \\
\hline never married & 14 & $26.21 \pm 11.21$ & \\
\hline married or in a civil partnership & 93 & $26.26 \pm 9.72$ & \\
\hline widowed & 72 & $23.63 \pm 10.44$ & \\
\hline divorced & 19 & $32.94 \pm 7.74$ & \\
\hline Place of residence & & & 0.0044 \\
\hline village & 17 & $18.11 \pm 7.29$ & \\
\hline \multicolumn{4}{|l|}{ town } \\
\hline$<50000$ residents & 26 & $29.19 \pm 10.57$ & \\
\hline $50000-100000$ residents & 112 & $26.14 \pm 9.32$ & \\
\hline$>100000$ residents & 43 & $26.31 \pm 10.33$ & \\
\hline Osteoporosis duration & & & 0.0762 \\
\hline $1-5$ years & 62 & $26.66 \pm 9.70$ & \\
\hline $6-10$ years & 60 & $26.56 \pm 10.66$ & \\
\hline $11-15$ years & 29 & $26.09 \pm 11.01$ & \\
\hline $16-20$ years & 34 & $25.57 \pm 9.99$ & \\
\hline$>20$ years & 13 & $21.53 \pm 9.48$ & \\
\hline Living conditions & & & $<0.0001$ \\
\hline very good & 17 & $26.82 \pm 10.51$ & \\
\hline good & 105 & $28.58 \pm 8.94$ & \\
\hline poor/bad & 51 & $24.86 \pm 10.80$ & \\
\hline very poor & 25 & $16.52 \pm 8.00$ & \\
\hline
\end{tabular}

Interpretation according to the AIS classification: 8-18 pts - low level, 19-29 pts - moderate level, 30-40 pts - high level [13,14].

* Kruskal-Wallis test. 
wska et al. [26] which indicate that perimenopausal women perceive osteoporosis as a moderately serious health problem and do not feel particularly burdened with the risk of developing the disease [26]. Additionally, as stated by the latest recommendations of diagnostic and therapeutic procedures in osteoporosis in Poland, it turns out that $80-90 \%$ of patients suffering from osteoporosis, including osteoporosis with fractures, do not receive adequate pharmacotherapy. That shows the scale of the problem of medical care for patients with osteoporosis [4].

The obtained results of authors' own research showed that most of the surveyed women had a high level of disease acceptance (41\%), while the analysis of mean values $(\mathrm{M} \pm \mathrm{SD} 25.95 \pm 10.2 \mathrm{pts})$ indicated a moderate disease acceptance level. It is due to 2 possible options for analysing the scale results. Such cases are described in the literature. In the study involving non-oncological patients by Dryhinicz and Rzepa [20] the mean disease acceptance score was high ( $\mathrm{M} \pm \mathrm{SD} 32.22 \pm 9.44 \mathrm{pts})$. However, according to the second type of scale interpretation, it remained at a moderate level [20]. In this study, the respondents' high scores may suggest that women accepted their chronic disease and felt it was well-controlled. On the other hand, their positive attitude may result from ignorance about the disease $[4,25,26]$. Higher acceptance of an illness improves cooperation between the patient and the physician, which translates into a better therapeutic effect. That is why it is so important to monitor the patient's level of disease acceptance and strive to improve it.

The next stage of the study was to establish the relationship between the disease acceptance level and sociodemographic variables. As a result of the statistical analysis, it was shown that younger women achieved a higher degree of disease acceptance compared to older ones. Similar observations in patients with osteoporosis were presented by Janiszewska et al. [14] and Pawlikowska-Łagód et al. [8]. Łuczyk et al. [16] also observed that the level of disease acceptance in a group of patients with unstable angina decreased with age.

The authors proved the impact of the place of residence on the level of disease acceptance. Worse results were observed in women living in the countryside, which is consistent with the observations made by Janiszewska et al. [14]. However, no relationship between a place of residence and a chronic disease was reported by Łuczyk et al. [16].

Another sociodemographic factor was the level of education which statistically significantly differentiated the disease acceptance degree. Pawlikowska-Łagód et al. [8] and Janiszewska et al. [14] found an unfavourable degree of disease acceptance among patients with lower education. It may result from the fact that patients with higher education have better awareness of the risks of non-compliance, so they are more likely to learn how to cope with osteoporosis, which contributes to greater acceptance of the disease [16].

The authors did not show any relationship between osteoporosis duration and the level of its acceptance. Different observations are presented by Łuczyk et al. [16] and Janiszewska et al. [14].

In the analysis of the patients, the authors found that the level of acceptance of postmenopausal osteoporosis statistically significantly depends, among others, on the place of residence, education and financial situation. Similar results were published by Janiszewska et al. [14] who proved that older age, low level of education, poor living conditions and prolonged illness were associated with lower disease acceptance. Nowicki et al. [27] presented similar results of surveyed Polish women with breast cancer at an early postoperative stage. Their study showed that the disease was best accepted by educated women living in cities, white-collar workers with a good economic situation [27]. It may result from an easier access to information, medical and psychological care. However, a study based on the Disease Acceptance Scale 
conducted by Gosicka [10] indicated that the level of disease acceptance among patients with chronic obstructive pulmonary disease did not statistically significantly depend on age or education level of the respondents but on their place of residence. Furthermore, while analyzing patients treated for mental disorders, Bogusz and Humeniuk [19] did not find that the disease acceptance level was correlated with independent variables, i.e., age, education or place of residence.

The strong point of this study study is the large number of the respondents. However, the group of people is not very diverse in terms of the region of residence. It would be advisable to extend the scope of the study to other voivodeships. Another important aspect the authors emphasize in this study is mental condition of patients with osteoporosis, which is not common in the case of individuals who do not report themselves to e.g. psychologists or psychiatrists. In the future, the authors would like to perform AIS at the beginning of the diagnosis and then at intervals of 6, 12 and 24 months. The study also has other limitations, as the authors did not analyze the disease acceptance status depending on the last densitometry result or the type of received treatment (tablets, injections). The authors admit that there is not any information on the impact of other chronic diseases that could affect the mental condition of the respondents, which should be the subject of further research.

\section{CONCLUSIONS}

It should be kept in mind that the level of disease acceptance in women with postmenopausal osteoporosis is significantly related to sociodemographic factors. The authors have shown that postmenopausal osteoporosis acceptance level significantly depends on age, place of residence, education and affluence, however, not on the duration of the disease. It would be advisable to develop disease awareness as well as rehabilitation and psychological programmes for patients. The aim of such projects would be to educate on osteoporosis and disseminate information on strategies that help to cope with the diagnosed disease. A multidisciplinary approach to treatment of women with postmenopausal osteoporosis is crucial, including essential psychological support, health education and improvement of social conditions.

\section{REFERENCES}

1. Misiak A. Factors Osteoporosis predisposing factors after 50 years old women's group- abilities of preventive and therapy proceedings. Long-Term Care Nursing. 2018;1, https:// doi.org/10.19251/pwod/2018.1(2).

2. Cauley JA. Public health impact of osteoporosis. J Gerontol A Biol Sci Med Sci. 2013;68(10):1243-51, https://doi.org/10. 1093/gerona/glt093.

3. Shin CS, Choi HJ, Kim MJ, Kim JT, Yu SH, Koo BK, et al. Prevalence and risk factors of osteoporosis in Korea: a community-based cohort study with lumbar spine and hip bone mineral density. Bone. 2010;47:378-87, https://doi.org/10. 1016/j.bone.2010.03.017.

4. Lorenc R, Głuszko P, Franek E, Jabłoński M, Jaworski M, Kalinka-Warzocha E, et al. Zalecenia postępowania diagnostycznego i leczniczego w osteoporozie w Polsce. Endokrynol Pol. 2017;68(supl. A):1-18.

5. Zanchetta J. Auditoria Regional da América Latina: Epidemiologia, custos e ônus da osteoporoseem 2012 [Internet]. Buenos Aires: International Osteoporosis Foundation; 2012 [cited 2015]. http://osteoporosisinlatinamerica.com/pt/wp content/uploads/2012/11/LA_Audit_Portugues.pdf.

6. Brondani JE, Comim FV, Flores LM, Araújo Martini L, Premaor MO. Fruit and vegetable intake and bones: A systematic review and meta-analysis. PloS one. 2019;14(5):e0217223, https://doi.org/10.1371/journal.pone.0217223.

7. Rolka H, Pilecka E, Kowalewska B, Krajewska-Kułak E, Jankowiak B, Klimaszewska K, et. al. Acceptance Evaluation of Disease and Quality of Life of Patients with a Pacemaker. Piel Zdr Publ. 2012;2(3):183-92. 
8. Pawlikowska-Łagód K, Janiszewska M, Firlej E, Dąbska O, Sak J. [Acceptance of diseases of women treated for osteoporosis]. J Educ Health Sport. 2016;6(5):139-48, https:// doi.org/10.5281/zenodo.51372.

9. Miniszewska J, Adamska M. Przekonania na temat zdrowia i choroby a akceptacja ograniczeń wynikających z przewlekłej choroby somatycznej na przykładzie osób z łuszczycą. Psych Psychol Klin. 2014;14(3):202-12.

10. Gościcka M. [Assessment of chronic disease acceptance based on the example of patients with chronic obstructive pulmonary disease]. Innov Nurs. 2016;2:63-78, https://doi. org/10.21784/IwP.2016.010.

11. Felton BJ, Revenson TA. Coping with chronic illness: a study of illness controllability and the influence of coping strategies on psychological adjustment. J Consult Clin Psychol. 1984;52(3):343-53.

12. Juczyński Z. Narzędzia Pomiaru w Promocji i Psychologii Zdrowia. Warszawa: Pracownia Testów Psychologicznych; 2012.

13. Krzyżanowska E, Matej A, Łuczyk R, et al. The impact of the acceptance of the disease on the health behaviors of patients with liver cirrhosis. J Educ Health Sport. 2016;6(11): 225-44.

14. Janiszewska M, Barańska A, Jędrych T, Kulik T, Kasperek J, Drop B. The impact of selected factors on acceptance of illness and life satisfaction among female residents of rural areas treated for osteoporosis. Ann Agric Environ Med. 2019;26(4):592-9, https://doi.org/10.26444/aaem/109598.

15. Kowalewska B, Cybulski M, Jankowiak B, Krajewska-Kułak E. Acceptance of Illness, Satisfaction with Life, Sense of Stigmatization, and Quality of Life among People with Psoriasis: A Cross-Sectional Study. Dermatol Ther (Heidelb). 2020;10(3):413-30, https://doi.org/10.6084/m9.figshare.11 932881.

16. Łuczyk R, Juśko A, Łuczyk M, Krzyżanowska E, Plottke A. Akceptacja choroby $\mathrm{w}$ grupie pacjentów $\mathrm{z}$ rozpoznaną dusznicą bolesną niestabilną. J Educ Health Sport. 2016;6(7): 453-70, http://dx.doi.org/10.5281/zenodo.58612.
17. Kurowska K, Kasprzyk A. Akceptacja choroby i style radzenia sobie ze stresem u osób dializowanych. Psychiatr Psychol Klin. 2013;13(2):99-107.

18. Staniszewska A, Religioni U, Dąbrowska-Bender M. Acceptance of disease and lifestyle modification after diagnosis among young adults with epilepsy. Patient Prefer Adherence. 2017;11:165-74, https://doi.org/10.2147/PPA.S126650.

19. Bogusz R, Humeniuk E. Psychosocial determinants of disease acceptance in selected mental disorders. Ann Agric Environ Med. 2017;24(4):644-7, https://doi.org/10.5604/ 12321966.1235164.

20. Dryhinicz M, Rzepa T. [The Level of Anxiety, Acceptance of Disease and Strategy of Coping with Stress in Patients Oncological and Non-oncological]. Annales UMCS Sectio J (Paedagogia-Psychologia); 2018;31(1), https://doi.org/10. 17951/j.2018.31.1.7-21. Polish.

21. Cipora E, Konieczny M, Sobieszczański J. Acceptance of illness by women with breast cancer. Ann Agric Environ Med. 2018;14;25(1):167-71, https://doi.org/10.26444/aaem/75876.

22. Czerw AI, Religioni U, Deptała A, et. al. Assessment of pain, acceptance of illness, adjustment to life with cancer, and coping strategies in colorectal cancer patients. Gastroenterology Rev. 2016;11(2):96-103, https://doi.org/10.5114/pg. 2015.52561.

23. Chabowski M, Polański J, Jankowska-Polanska B, Lomper K, Janczak D, Rosinczuk J. The acceptance of illness, the intensity of pain and the quality of life in patients with lung cancer. J Thorac Dis. 2017;9(9): 2952-8, https://doi. org/10.21037/jtd.2017.08.70.

24. Krajewski W, Mazur M, Poterek A, Pastuszak A, Halska U, Tukiendorf A, et. al. Assessment of Pain Management, Acceptance of Illness, and Adjustment to Life with Cancer in Patients with Non muscle Invasive Bladder Cancer. Biomed Res Int. 2018;7598632, https://doi.org/10.1155/ 2018/7598632.

25. Janiszewska M, Kulik T, Dziedzic M, Żołnierczuk-Kieliszek D, Jarosz MJ. Knowledge of osteoporosis prophylaxis and health behaviours of the population of chosen countries 
of the world. Ann Agric Environ Med. 2014;21(2):364-8, https://doi.org/10.5604/1232-1966.1108606.

26. Janiszewska M, Firlej E, Dziedzic M, Żołnierczuk-Kieliszek D. Health beliefs and sense of one's own efficacy and prophylaxis of osteoporosis in peri- and post-menopausal women. Ann Agric Environ Med. 2016;23(1):167-73, https://doi.org/10.5604/12321966.1196875.
27. Nowicki A, Krzemkowska E, Rhone P. Acceptance of Illness after Surgery in Patients with Breast Cancer in the Early Postoperative Period. Pol Przegl Chirurg. 2015;87(11):539-50, https://doi.org/10.1515/pjs-2016-0001.

This work is available in Open Access model and licensed under a Creative Commons Attribution-NonCommercial 3.0 Poland License - http://creativecommons.org/ licenses/by-nc/3.0/pl/deed.en. 